\title{
Effect of dried nut fortification on functional, physicochemical, textural, and microbiological properties of yogurt
}

\author{
S. Ozturkoglu-Budak, ${ }^{1}$ C. Akal, and A. Yetisemiyen \\ Department of Dairy Technology, Faculty of Agriculture, Ankara University, 06110 Ankara, Turkey
}

\begin{abstract}
In this study, walnut, hazelnut, almond, or pistachio were incorporated to produce functional yogurts. The effects on physicochemical and instrumental textural characteristics and syneresis, contents of folic acid, selenium, tocopherols, and n-3 and n-6 (omega) fatty acids, and viable counts of Streptococcus thermophilus and Lactobacillus bulgaricus were evaluated during storage. Fortified yogurts demonstrated higher protein and total solid contents and lower syneresis compared with control yogurt on d 21. Addition of nuts, except walnut, also increased $S$. thermophilus and L. bulgaricus counts. The concentrations of folic acid, $\alpha$-tocopherol, selenium, and n-3 and n-6 fatty acids were higher in fortified yogurts compared with the levels found in the respective nut types. However, a decreasing trend was observed in all components during storage. Consequently, each nut could be incorporated into yogurt because of a specific functional property. For instance, walnut could be preferred for omega acid enrichment. Key words: nut, fortification, yogurt, functional
\end{abstract}

\section{INTRODUCTION}

Yogurt has an important role in human nutrition due to its nutritional value from proteins, lactose, calcium, and water-soluble vitamins. Although its many healthy and nutritious effects are well known, milk and its products are not usually considered as a rich source for bioactive components. As consumers demand healthy foods with good taste, some functional milk products have been produced by means of enrichment and fortification in recent years. In this manner, yogurt has begun to attract new consumer groups because of its pleasant taste and increased health benefits.

Food fortification is defined as the supplementation of one or more components, regardless of whether it

Received March 24, 2016.

Accepted August 3, 2016.

${ }^{1}$ Corresponding author: budak@ankara.edu.tr is naturally found in the food, to improve the properties of newly designed functional food products (Świeca et al., 2014). Functional foods have the potential to improve mental and physical status and to reduce risks of diseases; these characteristics generally stem from some useful components, called bioactive compounds (Biesalski et al., 2009).

Nuts constitute a good source of bioactive compounds, such as UFA, high-quality vegetable protein, fiber, minerals, tocopherols, phytosterols, and phenolic compounds (Ros, 2010). Thus, nuts provide many health benefits, such as a reduced incidence of several chronic diseases including cardiovascular disease (Kris-Etherton et al., 2001), a lower risk of BW gain and obesity (Bes-Rastrollo et al., 2009), and a cholesterol-reducing effect (Chisholm et al., 2005) in human beings. Among the various bioactive compounds present in nuts, folic acid, selenium, n-3 and n-6 fatty acids, and vitamin $\mathrm{E}$ are among the most important because of their reported beneficial health effects; dairy products do not particularly constitute a good source of these components. For example, cow milk provides 5 to $7 \mu \mathrm{g} / 100 \mathrm{~g}$ of folic acid (Boeneke and Aryana, 2008), but the daily recommended intake of dietary folate is $400 \mu \mathrm{g}$ for an adult and 400 to $600 \mu \mathrm{g}$ for pregnant women (Menard, 1997). Folic acid is considered an important vitamin in the prevention of neural tube defects. Similarly, the recommended daily intake of selenium is $55 \mu \mathrm{g}$ for adults and $70 \mu \mathrm{g}$ for pregnant women and nursing mothers (Palomo et al., 2014). Tocopherol acts as an antioxidant in the body, protecting cell membranes, active enzyme sites, and DNA from free radical damage; recommended daily intake of tocopherol is $15 \mathrm{mg}$ (Ribarova et al., 2003). Folic acid, selenium, and tocopherol have been shown to reduce the risk of cancer and cardiovascular disorders (Roman et al., 2010). Omega fatty acids are reported to prevent the metabolic syndrome caused by risk factors such as cardiovascular disease, abdominal obesity, hypertension, and high fasting glycemia (de Camargo Talon et al., 2015). The recommended daily intakes of eicosapentaenoic (EPA) or docosahexaenoic acid (DHA) and $\alpha$-linolenic acid are $250 \mathrm{mg}$ and 2 g, respectively (European Council, 2006). The main 
sources of n-6 fatty acids are corn and soybean oils, which include high amounts of linoleic acid, and n-3 fatty acids are found at high levels in dried nuts, such as walnut and flaxseed, and in oily fish (Benito et al., 2006); however, because of their characteristic fishy flavor, the use of marine sources in dairy products is very limited.

Another advantage of using nuts as a fortifier in yogurt is their substantial dietary fiber (Bertolino et al., 2015) and protein contents (Harris and Ferguson, 2013). Taking this into account, nut supplementation may effectively increase the TS content of yogurt, which is important for gel formation, firmness, viscosity, and syneresis of yogurt (Matumoto-Pintro et al., 2011); likewise, nuts could be classified as sources of prebiotics with nondigestible carbohydrates (Sah et al., 2016).

Many studies have been done on fortifying and expanding the nutritional quality of yogurts, including the addition of folic acid (Boeneke and Aryana, 2008), selenium (Palomo et al., 2014), phenolic compounds (Pelaes Vital et al., 2015), and dietary fiber (Sah et al., 2016); however, only one study examined the addition of hazelnut to yogurt (Bertolino et al., 2015), in which the effect of dietary fiber on the mechanical properties of yogurt was investigated. In studies in which foods have been fortified with folic acid, selenium, and omega fatty acids, synthetic forms of these components obtained from industrial suppliers were used instead of natural components extracted from a food or a natural food itself. Although the addition of nuts increases the cost of yogurt about 42 to $86 \%$, such products would be preferred due to their high nutritional benefits.

In recent years, use of natural ingredients, instead of artificial supplements, has gained importance in terms of food safety. The main objective of the current study was to fortify yogurt with natural dried nuts, such as walnut, hazelnut, almond, and pistachio, which are rich in bioactive compounds, and to determine the effect of dried nuts on the functional, physicochemical, instrumental textural, and microbiological properties of yogurt during $21 \mathrm{~d}$ of storage. We hypothesized that the composition of certain bioactive components examined in nuts would be useful for the production of new functional products.

\section{MATERIALS AND METHODS}

\section{Materials}

Raw bovine milk was supplied by the Ankara University Dairy Plant (Ankara, Turkey). The starter culture containing Streptococcus thermophilus and Lactobacillus delbrueckii ssp. bulgaricus (DVS CH1, Chr.
Hansen, Hørsholm, Denmark) was prepared according to the manufacturer's instructions. All chemicals used for analysis were purchased from Merck (Darmstadt, Germany) and standards were supplied by Supelco/ Sigma-Aldrich (St. Louis, MO) with $99 \%$ purity. Ultrapure water was produced by ELGA PureLab Option-Q System (Buckinghamshire, UK).

\section{Dried Nut Samples}

The hazelnut, walnut, almond, and pistachio nuts each came from single lots, purchased in roasted and unsalted form from Kesimal Dried Nuts Company (Ankara, Turkey). Each nut was analyzed and certified by provider as aflatoxin-free. All nuts were ground individually with a stainless steel laboratory blender (Waring Commercial Blender, Torrington, CT). The particle size of the ground nuts was standardized to 0.5 mm using sieves (Mesh Series, Endecotts Ltd., London, $\mathrm{UK}$ ) and underwent a second roasting at $150^{\circ} \mathrm{C}$ for 20 min in an industrial continuously working oven to obtain a sterilized nut and firm structure.

\section{Yogurt Production}

Yogurt samples were produced in the Department of Dairy Technology, Ankara University (Ankara, Turkey). Fresh raw milk with $3.6 \%$ (wt/vol) fat content was standardized to $3.0 \%$ (wt/vol), and TS content was standardized to $16 \%$ by the addition of skim milk [containing 9.0\% (wt/vol) TS and 0.1 (wt/vol) fat]. Standardized milk was homogenized under pressure of $1.5 \times 10^{7} \mathrm{~N} / \mathrm{m}^{2}$ at $70^{\circ} \mathrm{C}$ and placed into stainless steel containers. Following homogenization, the milk was heated at $90^{\circ} \mathrm{C}$ for $5 \mathrm{~min}$, and then rapidly cooled to $45^{\circ} \mathrm{C}$ and inoculated with starter culture at a rate of $2 \%$ (vol/vol). Incubation was carried out at $43^{\circ} \mathrm{C}$ until the $\mathrm{pH}$ of 4.6 was achieved at an approximate incubation period of $4 \mathrm{~h}$. At that point, fermentation was stopped by cooling to $4^{\circ} \mathrm{C}$. In total, $25 \mathrm{~kg}$ of set-type yogurt was produced in each repetition. After the coagulum was broken with a skimmer and divided into 5 equal portions, 4 portions were supplemented with respective ground nut samples at a ratio of $5 \%$ (wt/wt), which was decided upon during preliminary studies, and the last portion was used as control sample. All productions were made in triplicate and each yogurt sample was stored at $4^{\circ} \mathrm{C}$ until analyses were performed on $\mathrm{d}$ $1,7,14$, and 21 .

\section{Microbiological Analyses}

Viable counts of S. thermophilus and L. bulgaricus were analyzed to identify the effect of nut addition on 
lactic acid bacteria count. Streptococci were counted on M17 agar (Merck) and were incubated aerobically at $37^{\circ} \mathrm{C}$ for $24 \mathrm{~h}$. Lactobacilli were counted on de Man, Rogosa, Sharpe agar (Merck) under anaerobic incubation at $37^{\circ} \mathrm{C}$ for $48 \mathrm{~h}$. All bacterial analyses were conducted in duplicate.

\section{Chemical Analyses}

The $\mathrm{pH}$ of the samples was measured by using a $\mathrm{pH}$ meter (MP225, Mettler-Toledo, Columbus, $\mathrm{OH}$ ) fitted with a standard combined electrode. The titratable acidity of the yogurts was determined according to the method reported by Bradley et al. (1993) and expressed as the lactic acid percentage. Total protein was analyzed by the Kjeldahl method (IDF, 1993) using a Büchi K435 digestion system and distillation unit (Büchi 323, Flawil, Switzerland). A multiplication factor of 6.38 was used to convert nitrogen percentage to protein percentage. Total solids and fat content were determined according to AOAC International (1997). The lipid fraction of nuts was extracted using a Soxhlet Velp Extraction System (VELP Scientifica, Usmate, Italy), by using $10 \mathrm{~g}$ of the dried and homogenized sample following a 6 -h extraction procedure at $60^{\circ} \mathrm{C}$ with $n$-hexane as solvent (Kornsteiner et al., 2006). All analyses were performed in triplicate.

\section{Susceptibility to Syneresis and Water-Holding Capacity}

Susceptibility to syneresis (STS) was evaluated according to the method of Isanga and Zhang (2009) by placing $100 \mathrm{~mL}$ of yogurt sample on a funnel lined with Whatman no. 1 filter paper (Whatman Int. Ltd., Maidstone, UK). After $6 \mathrm{~h}$ of drainage, separated whey was measured and used as index of syneresis. The following formula was used for the calculation of STS:

$$
\operatorname{STS}(\%)=\left(V_{1} / V_{2}\right) \times 100,
$$

where $V_{1}$ is the volume of whey collected after drainage and $V_{2}$ is the volume of yogurt sample.

The water-holding capacity (WHC) of yogurts was measured by the centrifugation (Sigma 3-18K, Sartorius AG, Göttingen, Germany) method of Isanga and Zhang (2009) with several modifications. Twenty-five grams of yogurt was centrifuged at 4,500 $\times g$ for $15 \mathrm{~min}$ at $4^{\circ} \mathrm{C}$ and $\mathrm{WHC}$ was calculated as follows:

$$
\operatorname{WHC}(\%)=\left(1-W_{1} / W_{2}\right) \times 100,
$$

where $W_{1}$ is the weight of whey after centrifugation and $W_{2}$ is the weight of yogurt sample. All measurements were carried out in triplicate.

\section{Instrumental Texture Analysis}

The firmness ( $\mathrm{g}$ of force) of the yogurt samples were measured by using a texture analyzer TA.XT Plus (Stable Micro Systems, Surrey, UK). The test was carried out directly in a 200-g plastic sample cup, using a 35-mm back extrusion probe (A/BE- d35, Stable Micro Systems) and a 5 -kg load cell. A cone probe was moved at a test speed of $10 \mathrm{~mm} / \mathrm{s}$ from the yogurt surface until a distance of $20 \mathrm{~mm}$ within the sample was reached. Firmness, which is peak compression force, was recorded from the force versus time graph and expressed in grams. Three different cups were measured for each sample.

\section{Folic Acid Analyses}

The folic acid concentrations of nuts and yogurt samples were determined according to the method of Stokes and Webb (1999) using an HPLC (Agilent 1100 HPLC System, Agilent Technologies, Santa Clara, CA) system. Briefly, $2.0 \mathrm{~g}$ of nut or yogurt sample was mixed with $40 \mathrm{~mL}$ of $75 \mathrm{~m} M$ ammonium acetate solution $(\mathrm{pH}=7)$, sonicated for $10 \mathrm{~min}$, and mixed in an orbital shaker for $60 \mathrm{~min}$. After extraction, the samples were centrifuged for $15 \mathrm{~min}$ at $1,400 \times g$ at $5^{\circ} \mathrm{C}$, and $50 \mu \mathrm{L}$ of the supernatant was taken and diluted with $700 \mu \mathrm{L}$ of water. A $50-\mu \mathrm{L}$ sample was passed through a $0.45-\mu \mathrm{m}$ filter (Millex, Millipore, Medford, MA) before injection into the HPLC. An HPLC system equipped with UV diode array detector (UV-DAD, Agilent Technologies) with an Aqua C18 column $(250 \times 4.6 \mathrm{~mm}$, $5 \mu \mathrm{m}$ ) and a temperature of $35^{\circ} \mathrm{C}$ was used for sample analyses. Mobile phases consisting of $2.5 \mathrm{~m} M$ acetic acid:acetonitrile $(88: 12)$ was used at a flow rate of 0.5 $\mathrm{mL} / \mathrm{min}$. Injection volume was $50 \mu \mathrm{L}$ and all injections were made in triplicate.

A standard curve was prepared at concentrations of $1.0,5.0,10,25$, and $50 \mathrm{ng} / \mathrm{mL}$ in a water solution containing $5.0 \mathrm{mmol} / \mathrm{L}$ of ammonium acetate. Peak area results from HPLC analysis were correlated with the standard curve to determine folic acid concentrations.

\section{Determination of Selenium}

A 0.5 -mg sample was digested with $5 \mathrm{~mL}$ of $\mathrm{HNO}_{3}: \mathrm{H}_{2} \mathrm{O}(65 \%, 65: 35 \mathrm{vol} / \mathrm{vol})$ and $2 \mathrm{~mL}$ of $\mathrm{H}_{2} \mathrm{O}_{2}: \mathrm{H}_{2} \mathrm{O}$ $(30 \%, 30: 70 \mathrm{vol} / \mathrm{vol})$ in a microwave oven at a pressure 
of $4.5 \times 10^{6} \mathrm{~N} / \mathrm{m}^{2}$ at $1,500 \mathrm{~W}$ for $15 \mathrm{~min}$ (CEM, Matthews, NC) using a Teflon-closed Parr bomb (Parr Instrument Co., Moline, IL). The vessel temperature was $200^{\circ} \mathrm{C}$ and oven temperature was $110^{\circ} \mathrm{C}$. Determination of selenium after acid digestion was performed according to (NMKL, 2007) by inductively coupled plasma mass spectrometry (ICP-MS $7500 \mathrm{Cx}$, Agilent). The operating parameters of ICP-MS for selenium detection were as follows: radio frequency power: $1,550 \mathrm{~W}$, carrier gas flow rate: $0.95 \mathrm{~L} / \mathrm{min}$, make-up gas: $0.10 \mathrm{~L} /$ min, nebulizer: Babington Technology (Rocky Mount, $\mathrm{NC}$ ), spray chamber temperature: $2^{\circ} \mathrm{C}$, octupole radio frequency ion trap voltage: $170 \mathrm{~V}$, and ion lens space: $-30 \mathrm{~V}$. Quantification was made according to the calibration curve of selenium standard.

\section{Determination of Tocopherols}

The content of vitamin $\mathrm{E}$ was quantified according to the method reported by Costa et al. (2010), with slight modifications. Vitamin E analyses were performed on extracted oil both from nuts and yogurt samples fortified with each of nut. The oil in the nuts and yogurts were extracted with $n$-hexane, after the stages of mixing stages in the shaker for $1 \mathrm{~h}$ and centrifuging at $3,060 \times g$ for $15 \mathrm{~min}$ at $5^{\circ} \mathrm{C}$ (Sigma 3-18K, Sartorius AG). Subsequently, the oil was obtained by solvent evaporation under nitrogen. Two hundred microliters from remnant oil was dissolved in $1,000 \mu \mathrm{L}$ of a $75: 25$ isopropanol:chloroform solution. All the stages were carried out without light. A $20-\mu \mathrm{L}$ sample from the homogenized mixture was injected into the HPLC system (Agilent 1100 HPLC System). Chromatographic separations were performed with UV detection at $295 \mathrm{~nm}$. An RP-C18 column $(150 \mathrm{~mm} \times 4.6 \mathrm{~mm} \times 5 \mu \mathrm{m}$; ACE121-1546, Advanced Chromatography Technologies Ltd., Aberdeen, UK) was used at a flow rate of $0.8 \mathrm{~mL} /$ min and a temperature of $25^{\circ} \mathrm{C}$. The mobile phase composition consisted of a mixture of 95:5 methanol:water (vol/vol). Quantification was made by external calibration, using the standards of DL- $\alpha$ tocopherol (4-7783, Supelco, Bellefonte, PA) and (+)- $\gamma$-tocopherol (4-7785, Supelco).

\section{Determination of $n-3$ and n-6 Fatty Acids}

Concentrations of n-3 and n- 6 fatty acids were determined in nut and yogurt samples. The FAME of samples were obtained by acidic transesterification following the method described by Folch et al. (1957). Fatty acid methyl esters were analyzed by GC using an Agilent-5890A gas chromatograph, equipped with an on-column injector and a flame ionization detector, using a polyethylene glycol capillary column (DB-23,
Supelco; $60 \mathrm{~m} \times 0.32 \mathrm{~mm}$ i.d. $\times 0.25 \mu \mathrm{m}$ film thickness). The GC oven program temperature was initial temperature of $50^{\circ} \mathrm{C}$ for $1 \mathrm{~min}$, increased at $4^{\circ} \mathrm{C} / \mathrm{min}$ to $180^{\circ} \mathrm{C}$, held for $5 \mathrm{~min}$, increased at $4^{\circ} \mathrm{C} / \mathrm{min}$ to $250^{\circ} \mathrm{C}$, and then held for an additional $10 \mathrm{~min}$. The injector and detector temperature was $250^{\circ} \mathrm{C}$. The carrier gas used was helium at a flow rate of $1.0 \mathrm{~mL} / \mathrm{min}$. Injection volume was $2.0 \mu \mathrm{L}$ with a split ratio of 1:10.

Individual PUFA peaks were identified by comparison of their retention times to those of standards of n-3 [18:3, $\alpha$-linolenic acid, 20:5, EPA, and 22:6, DHA], n-6 [linoleic acid (18:2n-6) and arachidonic acid (20:4n6 ); Sigma-Aldrich]. Peak areas were measured and expressed in milligrams per $100 \mathrm{~g}$.

\section{Statistical Analysis}

A randomized complete block design that incorporated 5 treatments, 4 storage periods, and 3 blocks (trials) was used to analyze the response variables relating to the characteristics of yogurt. The differences between the evaluated responses during storage were determined using the ANOVA and SPSS Statistics software version 22.0 (IBM Corp., Armonk, NY). One-way ANOVA, followed by Duncan's multiple comparison test was used for statistical analysis to determine levels of significant difference $(P<0.05)$ between treatments.

\section{RESULTS AND DISCUSSION}

\section{Viability of Yogurt Bacteria}

Figure 1 shows $S$. thermophilus and L. bulgaricus counts in all yogurts. The viable counts of $S$. thermophilus and L. bulgaricus decreased slightly or remained constant during storage in control yogurt $(P>0.05)$. However, fortification of yogurt with hazelnut, almond, or pistachio resulted an increase in S. thermophilus counts. The highest and lowest counts of streptococci were detected in pistachio- and walnut-added yogurt, respectively. The increase rate of $S$. thermophilus was obtained between the range of 1 to $2 \log$ compared with control yogurt and the mean count of streptococci showed a tendency to increase over the $21 \mathrm{~d}$ of storage.

Except for walnut, L. bulgaricus values were also higher in fortified yogurts compared with control yogurt $(P<0.05)$ on $\mathrm{d} 1$ of storage, whereas the mean count of lactobacilli increased until d 7 of storage. Slight decreases were observed thereafter in all fortified yogurts. Yogurt samples fortified with almond had the highest counts of L. bulgaricus, whereas the lowest count was determined in walnut-fortified yogurt, similar to S. thermophilus. The low S. thermophilus counts in walnut-fortified yogurt could be attributed to the 
inhibitory effect of antimicrobial and phenolic agents present in walnut (Pereira et al., 2007) on the growth of lactic acid bacteria strains. Naphthoquinone from walnut (juglone) is reported to have a cytotoxic effect, including the induction of oxidative stress, cell membrane damage, and clastogenic action, leading to cell death by apoptosis and necrosis (Aithal et al., 2009). This could explain why viable counts in walnut-fortified yogurt were $<7 \log \mathrm{cfu} / \mathrm{mL}$, the minimum standard for lactic acid bacteria set by the Codex Alimentarius for yogurts, even on d 1 of storage (Codex Alimentarius, 2011). Hazelnut-, almond-, and pistachio-fortified yogurts showed higher counts for both $S$. thermophilus and $L$. bulgaricus compared with control yogurt; therefore, we cannot comment on any antimicrobial effects demonstrated by relevant nut types.

Some authors have reported a decrease in the counts of yogurt bacteria during refrigerated storage (CaisSokolinska and Pikul, 2004). Vasiljevic et al. (2007) investigated the effect of addition of some supplements
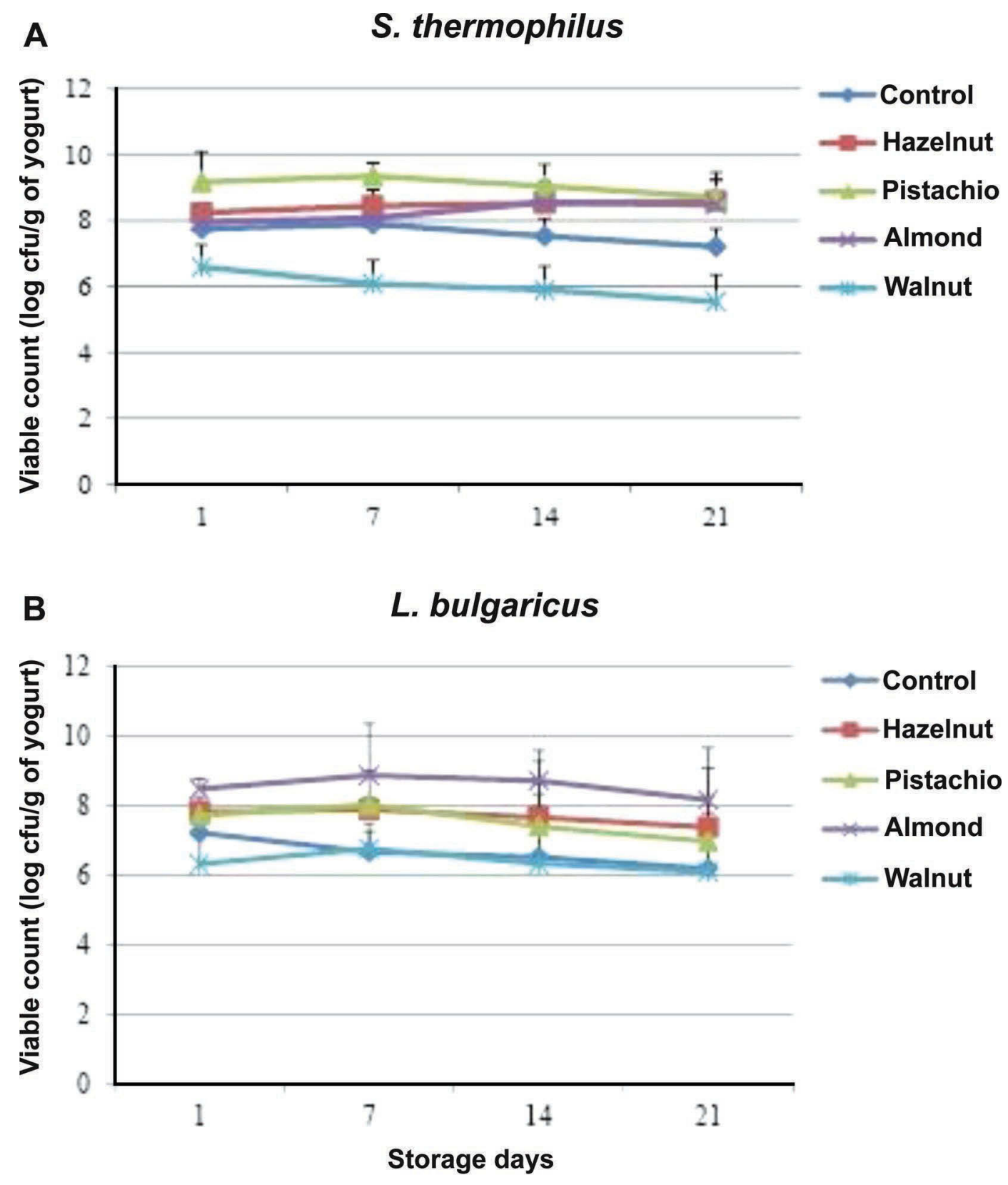

Figure 1. Viable counts (log cfu/g) of (A) Streptococcus thermophilus and (B) Lactobacillus bulgaricus in yogurts fortified with different nut types. Color version available online. 
used as prebiotics to mixed cultures of $S$. thermophilus and L. bulgaricus during storage and observed a slight but not significant increase in cell concentrations. Pelaes Vital et al. (2015) observed that yogurt supplemented with Pleurotus ostreatus extract, which is rich in bioactive compounds such as phenolic components and dietary fiber, caused significant changes in populations of lactic acid bacteria compared with control yogurt. Some other researchers who used dietary fiber from pineapple (Sah et al., 2016) and orange (GarcíaPérez et al., 2005) reported that dietary fiber provided additional source of carbohydrate for lactic acid bacteria and had a strong positive effect on the activity of some lactic acid bacteria strains. Contrary to our results, Bertolino et al. (2015) concluded that addition of hazelnut skin did not affect the survival of the mixed starter strains; however, mean concentrations of $L$. bulgaricus and $S$. thermophilus were slightly lower than those of the control yogurt samples, specifically at the end of storage.

\section{Composition of Yogurts}

Table 1 shows the average composition of yogurts fortified with different nut types compared with control yogurt. The $\mathrm{pH}$ values of all fortified yogurts were higher than that of control yogurt during the whole storage period. Titratable acidities of fortified yogurts were lower than that of control yogurt on $\mathrm{d} 1$ and 7 , whereas acidity was higher on d 14 and $21(P<0.01)$. The initial higher $\mathrm{pH}$ was a result of increased buffering capacity due to the additional proteins in the system, and the lower $\mathrm{pH}$ after 14 and $21 \mathrm{~d}$ of storage was due to increased growth of lactic acid bacteria. Similarly, Lee and Lucey (2010) concluded that additional proteins led to an increase in solid content of yogurt milk, thereby increasing buffering capacity that required additional acid development by starter cultures to achieve a similar $\mathrm{pH}$ target. The higher $\mathrm{pH}$ and lower acidity obtained in the current study could be due to the dietary fiber and proteins coming from nuts. During storage, $\mathrm{pH}$ values $(P<0.05)$ decreased slightly and titratable acidity $(P<0.01)$ showed a tendency to increase in all sample products. Hazelnut-fortified yogurt had the highest $\mathrm{pH}$ reduction (0.12 unit), whereas pistachiofortified yogurts had the highest $\mathrm{pH}$ value on both $\mathrm{d}$ 1 and 21. In terms of titratable acidity, the differences were mainly observed between pistachio-, almond-, and walnut-fortified yogurts over time. All yogurts fortified with each nut type had significantly higher values of TS than control yogurt $(P<0.01)$. However, during storage, no significant difference was detected in TS values. Similarly, total protein values were higher in the yogurts fortified with nuts $(P<0.01)$. The highest protein contents were detected in pistachio- and almond-fortified yogurts; this was probably due to the high protein content of each nut (almond: $21.14 \%$, pistachio: $20.95 \%$, hazelnut: $16.73 \%$, walnut: $16.05 \%$ ). In terms of fat content, differences were observed among samples, and the differences were parallel to the oil content of each nut (walnut: $69.54 \%$, hazelnut: $63.46 \%$, pistachio: $60.12 \%$, almond: $52.37 \%$ ) used for preparation of yogurts. Total protein and fat values did not show notable changes during storage period $(P<0.05)$.

\section{Syneresis and Water-Holding Capacity}

Whey syneresis and water-holding capacity values are demonstrated in Table 1. Syneresis was higher in fortified yogurts compared with control yogurt on d 1 and 7 , whereas control yogurt showed higher syneresis $(P<0.01)$ than fortified yogurts as storage progressed. As for water-holding capacity, the values of all yogurts were similar on d 1. During storage, syneresis values in all yogurt samples showed an increasing trend, except for almond-fortified yogurt; however, the increase was greatest in control yogurt from 30.69 to $52.38 \%$. Among fortified yogurts, the highest amount of syneresis was observed in walnut-fortified yogurt on d 21. Minimal syneresis was observed in almond-fortified yogurt on the same storage day. Contrary to syneresis data, a decrease was observed in water-holding capacity of all yogurts on d 7 and $14(P>0.01)$, whereas a significant increase was observed in water-holding capacity on d 21 among all 5 yogurt samples $(P<0.05)$. At the end of the storage period, water-holding capacities of control and fortified yogurts showed similar values, whereas that of control sample was lower than that of fortified samples $(P>0.01)$ except for the walnut-fortified yogurt.

Higher TS content of fortified yogurt may have played an important role in the lesser whey separation (Meyer et al., 2011) compared with control yogurt at the end of storage. It has also been reported in previous studies that high fat content of yogurt is related to lower syneresis amounts (Isanga and Zhang, 2009). As syneresis is the deterioration of the protein network and the loss of the ability of the yogurt gel to retain the serum phase (Lucey, 2002), the stirring stage with nuts might stimulate syneresis in our study. The increase observed in syneresis during the storage period is usually associated with casein rearrangement, in which casein micelles break, leading to whey separation. Increased acidity during storage could have been the stimulating factor for syneresis (Tamime and Robinson, 1999). Our results agree with previous reports that showed 
increasing syneresis in stirred yogurt supplemented with dietary fiber (Ramirez-Santiago et al., 2010) and polyphenols (Pelaes Vital et al., 2015) during storage.

Wu et al. (2001) observed that water-holding capacity is due to the ability of the proteins to retain water in the structure of yogurt. In addition, Wu et al. (2001) reported that milk fat globules have a water-retaining effect. In our study, the slightly higher water-holding capacities observed in fortified yogurts toward the end of storage might be explained by the enriched protein and fat content of fortified yogurts arising from nut composition. This might be attributed to the different properties of proteins present in nuts, with intrinsic factors such as food proteins, AA composition, protein conformation, and surface polarity or hydrophobicity that are reported to enhance water-holding capacity (Barbut, 1999).

\section{Instrumental Textural Characteristics}

The firmness values of yogurts fortified with various nut types are shown in Table 2. Control yogurt sample had the lowest firmness value on d 1 and 7 , whereas during storage firmness in the control yogurt

Table 1. Physicochemical characteristics of yogurts fortified with different nut types (mean $\pm \mathrm{SD} ; \mathrm{n}=3$ )

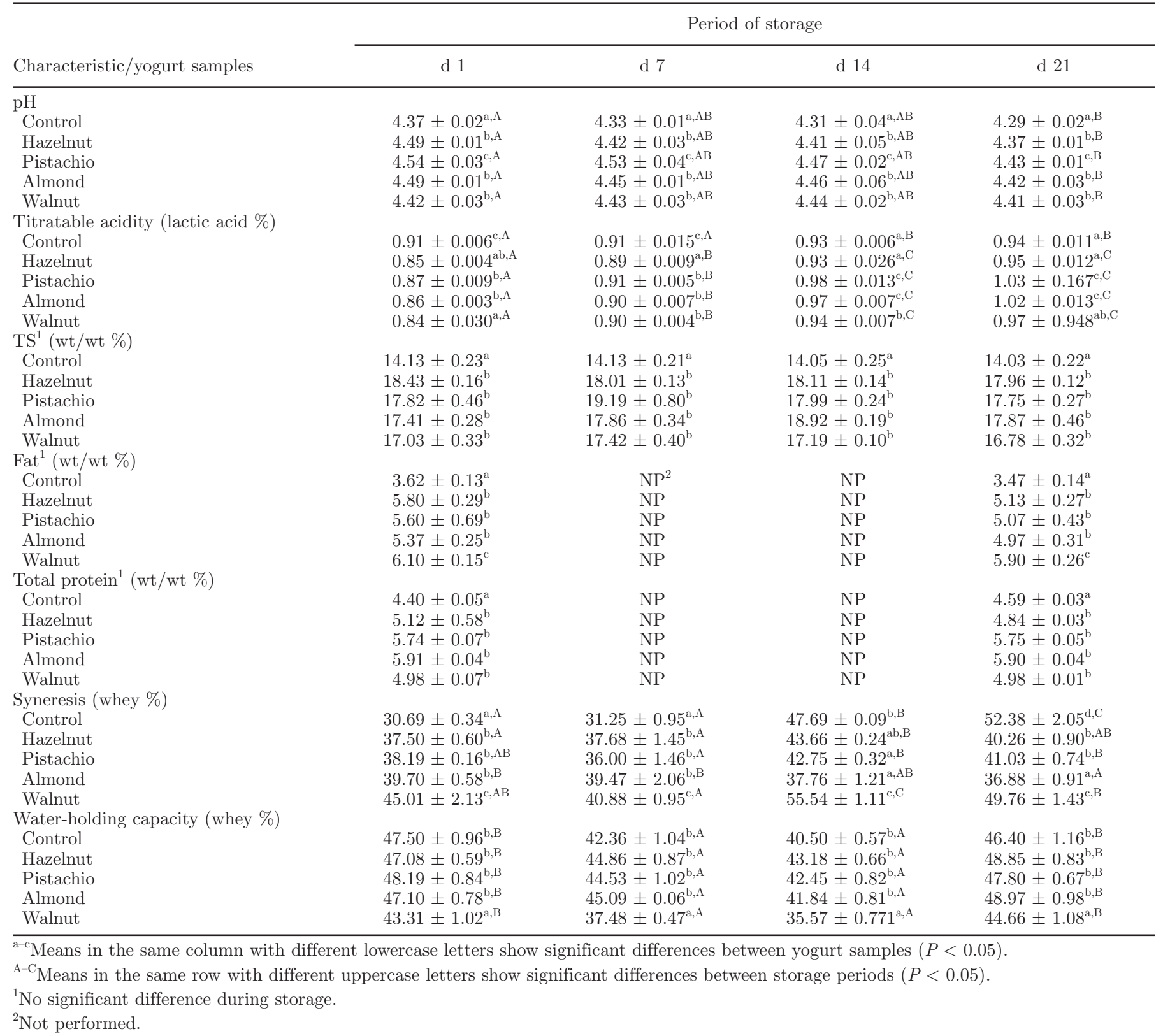


Table 2. Firmness (g of force; mean $\pm \mathrm{SD}$ ) of yogurts fortified with different nut types

\begin{tabular}{|c|c|c|c|c|}
\hline \multirow[b]{2}{*}{ Yogurt type } & \multicolumn{4}{|c|}{ Period of storage } \\
\hline & d 1 & d 7 & d 14 & d 21 \\
\hline $\begin{array}{l}\text { Control } \\
\text { Hazelnut } \\
\text { Pistachio } \\
\text { Almond } \\
\text { Walnut }\end{array}$ & $\begin{array}{l}54.87 \pm 0.521^{\mathrm{a}, \mathrm{B}} \\
62.50 \pm 3.10^{\mathrm{a}, \mathrm{A}} \\
56.76 \pm 1.11^{\mathrm{a}, \mathrm{A}} \\
61.13 \pm 3.09^{\mathrm{a}, \mathrm{B}} \\
55.54 \pm 4.97^{\mathrm{a}, \mathrm{B}}\end{array}$ & $\begin{array}{l}60.55 \pm 2.60^{\mathrm{a}, \mathrm{B}} \\
63.66 \pm 0.67^{\mathrm{a}, \mathrm{A}} \\
60.68 \pm 0.81^{\mathrm{a}, \mathrm{A}} \\
67.35 \pm 2.69^{\mathrm{a}, \mathrm{AB}} \\
65.59 \pm 1.79^{\mathrm{a}, \mathrm{AB}}\end{array}$ & $\begin{array}{l}73.80 \pm 1.79^{\mathrm{a}, \mathrm{A}} \\
66.69 \pm 1.54^{\mathrm{ab}, \mathrm{A}} \\
59.64 \pm 2.54^{\mathrm{b}, \mathrm{A}} \\
68.37 \pm 0.12^{\mathrm{ab}, \mathrm{A}} \\
68.60 \pm 4.18^{\mathrm{ab}, \mathrm{A}}\end{array}$ & $\begin{array}{l}80.59 \pm 0.75^{\mathrm{a}, \mathrm{A}} \\
72.88 \pm 6.30^{\mathrm{ab}, \mathrm{A}} \\
64.27 \pm 0.31^{\mathrm{bc}, \mathrm{A}} \\
76.48 \pm 0.17^{\mathrm{a}, \mathrm{AB}} \\
59.45 \pm 0.25^{\mathrm{c}, \mathrm{AB}}\end{array}$ \\
\hline
\end{tabular}

showed an increasing trend and had the highest value among all yogurts on d 21. Firmness showed similar $(P>0.01)$ values among the fortified yogurts on $\mathrm{d}$ 1 , whereas values showed significant differences $(P<$ $0.01)$ on $\mathrm{d} 21$. The firmness of all 5 yogurts increased during storage $(P<0.01)$; the increase was highest in control yogurt and lowest in walnut-fortified yogurt. Firmness of walnut-fortified yogurt increased during the first $14 \mathrm{~d}$ but decreased until the end of storage, although the firmness at the end of storage was higher than the value obtained on $\mathrm{d} 1$. The highest firmness among the fortified yogurts was observed in almond-and hazelnut-fortified yogurts, and the lowest firmness was detected in walnut-fortified yogurt at the end of storage. The physical and sensory properties of yogurt gels are greatly influenced by the TS content of the yogurt milk, especially the protein content (Biliaderis et al., 1992). Supplementation of nuts into yogurt increased whey separation compared with control yogurt on d 1 and 7 , which could be due to the breaking effect of nuts on the gel structure and a subsequent rearrangement of the gel matrix originating from the protein and dietary fibers in their structure, as previously reported (GarcíaPérez et al., 2005; Tseng and Zhao, 2013; Bertolino et al., 2015). Stirring the yogurt might also have an effect on breaking down the coagulated milk and increase syneresis (Tseng and Zhao, 2013). However, as storage progressed, syneresis in fortified yogurts decreased, which might be due to the higher water-holding capacity of the fibers in the structure of nuts and absorption of the released whey by these fibers, except for walnut-added yogurt (García-Pérez et al., 2005). These results could be related to instrumental textural properties in which fortified yogurts demonstrated a higher firmness on $\mathrm{d} 1$ and 7 but lower firmness on d 14 and 21 compared with control yogurt.

\section{Folic Acid Content}

Table 3 shows the folic acid values of different nut types and the yogurts fortified with those nuts. All fortified yogurts showed a higher folic acid content than the control yogurt $(P<0.01)$. Yogurt samples fortified with walnut and almond had higher concentrations of

Table 3. Folic acid and selenium contents $(\mu \mathrm{g} / 100 \mathrm{~g})$ of different kinds of nuts and fortified yogurts during storage $($ mean \pm SD; $\mathrm{n}=3$ )

\begin{tabular}{|c|c|c|c|c|c|c|}
\hline Nut samples & $\begin{array}{c}\text { Supplemental } \\
\text { amount }(\mu \mathrm{g} / 100 \mathrm{~g})\end{array}$ & $\begin{array}{l}\text { Yogurt } \\
\text { samples }\end{array}$ & \multicolumn{4}{|c|}{ Period of storage } \\
\hline Hazelnut & $178.84 \pm 9.48^{\mathrm{a}}$ & Hazelnut & $18.01 \pm 0.89^{\mathrm{b}, \mathrm{B}}$ & $17.25 \pm 1.54^{\mathrm{b}, \mathrm{AB}}$ & $17.10 \pm 7.31^{\mathrm{b}, \mathrm{AB}}$ & $16.76 \pm 1.18^{\mathrm{b}, \mathrm{A}}$ \\
\hline Pistachio & $185.19 \pm 13.21^{\mathrm{a}}$ & Pistachio & $18.26 \pm 2.56^{\mathrm{b}, \mathrm{B}}$ & $17.65 \pm 2.53^{\mathrm{b}, \mathrm{A}}$ & $17.80 \pm 4.27^{\mathrm{b}, \mathrm{A}}$ & $17.44 \pm 5.86^{\mathrm{b}, \mathrm{A}}$ \\
\hline Almond & $226.66 \pm 22.55^{\mathrm{b}}$ & Almond & $20.44 \pm 5.13^{\mathrm{b}, \mathrm{A}}$ & $19.82 \pm 8.11^{\mathrm{b}, \mathrm{A}}$ & $19.55 \pm 2.66^{\mathrm{b}, \mathrm{A}}$ & $19.16 \pm 6.75^{\mathrm{b}, \mathrm{A}}$ \\
\hline No supplement & & Control & $1.23 \pm 0.29^{\mathrm{a}, \mathrm{B}}$ & $1.22 \pm 0.10^{\mathrm{a}, \mathrm{AB}}$ & $1.24 \pm 0.18^{\mathrm{a}, \mathrm{B}}$ & $1.20 \pm 0.21^{\mathrm{a}, \mathrm{A}}$ \\
\hline Hazelnut & $1.58 \pm 0.07^{\mathrm{a}}$ & Hazelnut & $1.30 \pm 0.24^{\mathrm{ab}, \mathrm{B}}$ & $1.31 \pm 0.07^{\mathrm{ab}, \mathrm{AB}}$ & $1.30 \pm 0.14^{\mathrm{ab}, \mathrm{B}}$ & $1.27 \pm 0.30^{\mathrm{ab}, \mathrm{A}}$ \\
\hline Pistachio & $11.58 \pm 1.34^{\mathrm{c}}$ & Pistachio & $2.65 \pm 0.96^{\mathrm{c}, \mathrm{B}}$ & $2.65 \pm 0.13^{\mathrm{c}, \mathrm{AB}}$ & $2.72 \pm 0.42^{\mathrm{c}, \mathrm{B}}$ & $2.78 \pm 0.26^{\mathrm{c}, \mathrm{A}}$ \\
\hline Almond & $1.87 \pm 0.69^{\mathrm{a}}$ & Almond & $1.26 \pm 0.27^{\mathrm{ab}, \mathrm{B}}$ & $1.29 \pm 0.15^{\mathrm{ab}, \mathrm{AB}}$ & $1.30 \pm 0.13^{\mathrm{ab}, \mathrm{B}}$ & $1.26 \pm 0.12^{\mathrm{ab}, \mathrm{A}}$ \\
\hline Walnut & $3.96 \pm 0.98^{\mathrm{b}}$ & Walnut & $1.83 \pm 0.62^{\mathrm{b}, \mathrm{B}}$ & $1.84 \pm 0.33^{\mathrm{b}, \mathrm{AB}}$ & $1.84 \pm 0.17^{\mathrm{b}, \mathrm{B}}$ & $1.89 \pm 0.13^{\mathrm{b}, \mathrm{A}}$ \\
\hline
\end{tabular}

${ }^{\mathrm{a}-\mathrm{c}}$ Means in the same column with different lowercase letters show significant differences between nuts or yogurt samples fortified with different nut types $(P<0.05)$.

${ }^{\mathrm{A}, \mathrm{B}}$ Means in the same row with different capital letters show significant differences between storage periods $(P<0.05)$. 
folic acid than samples fortified with pistachio and hazelnut $(P<0.01)$.

We determined that control yogurt had amounts of folic acid that could have arisen from lactic acid bacteria. Laiño et al. (2012) reported that some strains of $L$. bulgaricus and $S$. thermophilus isolated from artisanal Argentinean yogurts produced high levels of extracellular folate (from 22.3 to $135 \mu \mathrm{g} / \mathrm{L}$ ). Another study reported that $S$. thermophilus was the dominant producer, elevating folate levels in skim milk yogurt from 11.5 $\mathrm{ng} / \mathrm{g}$ to between 40 and $50 \mathrm{ng} / \mathrm{g}$, whereas lactobacilli depleted the available folate. An increase in folic acid concentrations in yogurt fermented with mixed cultures was reported by Crittenden et al. (2003); in contrast, in our study, the amount of folic acid in control yogurt was $9.05 \mu \mathrm{g} / 100 \mathrm{~g}$ on $\mathrm{d} 1$ and decreased gradually during the storage period to $7.75 \mu \mathrm{g} / 100 \mathrm{~g}$ on $\mathrm{d} 21$. This result agrees with those of Lin and Young (2000) and Boeneke and Aryana (2008), who observed a decrease in folic acid concentration of yogurt during storage. A similar trend of folic acid decrease was also observed in all fortified yogurts during the storage period.

\section{Selenium Content}

Concentrations of selenium determined in the nut samples (Table 3) ranged from 1.58 to $11.49 \mu \mathrm{g} / 100$ $\mathrm{g}$. These values are within the range of values reported previously (1-20 $\mu \mathrm{g} / 100 \mathrm{~g})$ in nuts (Thomson, 2011). The highest concentration of selenium was determined in the yogurt samples with pistachio $(2.65-2.78 \mu \mathrm{g} / 100$ g) and the lowest concentration in samples with almond $(1.26-1.30 \mu \mathrm{g} / 100 \mathrm{~g})$. Fortification of yogurts with nuts did not change the selenium content of yogurts significantly $(P>0.01)$ other than pistachio and walnut $(P$ $<0.01)$. Yogurt samples with almond and hazelnut had similar low concentrations of selenium, which were very close to the value determined in control yogurt $(P>0.01)$. The selenium concentrations obtained in fortified yogurts corresponded with the values detected in the nut samples used for fortification. Selenium concentrations of nuts and control yogurt determined in our study agree with those of Barclay et al. (1995), who found values of $1.5 \mu \mathrm{g} / 100 \mathrm{~g}$ in yogurt and 3.1, 2 , and $1.5 \mu \mathrm{g} / 100 \mathrm{~g}$ in walnut, hazelnut, and almond, respectively. Demirel et al. (2008) also reported that selenium concentrations of pistachio and walnut grown in Turkey were 0.103 and $0.028 \mu \mathrm{g} / \mathrm{g}$, respectively. Except for pistachio yogurt, selenium concentrations in all fortified yogurts decreased slightly during storage and significant differences were observed on d 21 compared with d $1(P<0.01)$ in all yogurts.

\section{Tocopherol Content}

$\alpha$-Tocopherol is the form of vitamin $\mathrm{E}$ that is preferentially absorbed and accumulated in humans (Rigotti, 2007). Fortification of yogurt with different nut types resulted in significant $(P<0.01)$ variations in $\alpha$-tocopherol content. The highest $\alpha$-tocopherol content was found in hazelnut-fortified yogurt (4.35-4.87 $\mathrm{mg} / 100 \mathrm{~g}$ of oil) and the lowest was found in walnutfortified yogurt (2.14-2.75 mg/100 g of oil) during storage (Table 4). The obtained results were proportional to the content of $\alpha$-tocopherol in the individual nut varieties, in which $\alpha$-tocopherol was present in highest concentration in hazelnut, followed by almond, pistachio, and walnut (Table 4).

Despite their low $\alpha$-tocopherol content, pistachio and walnuts contain high levels of $\gamma$-tocopherol. $\alpha$-Tocopherol is assumed to be the most active form in humans; however, $\gamma$-tocopherol is reported to be the

Table 4. $\alpha$ - and $\gamma$-Tocopherol values $(\mathrm{mg} / 100 \mathrm{~g}$ of oil) of different types of nuts and fortified yogurts during storage (mean $\pm \mathrm{SD} ; \mathrm{n}=3$ )

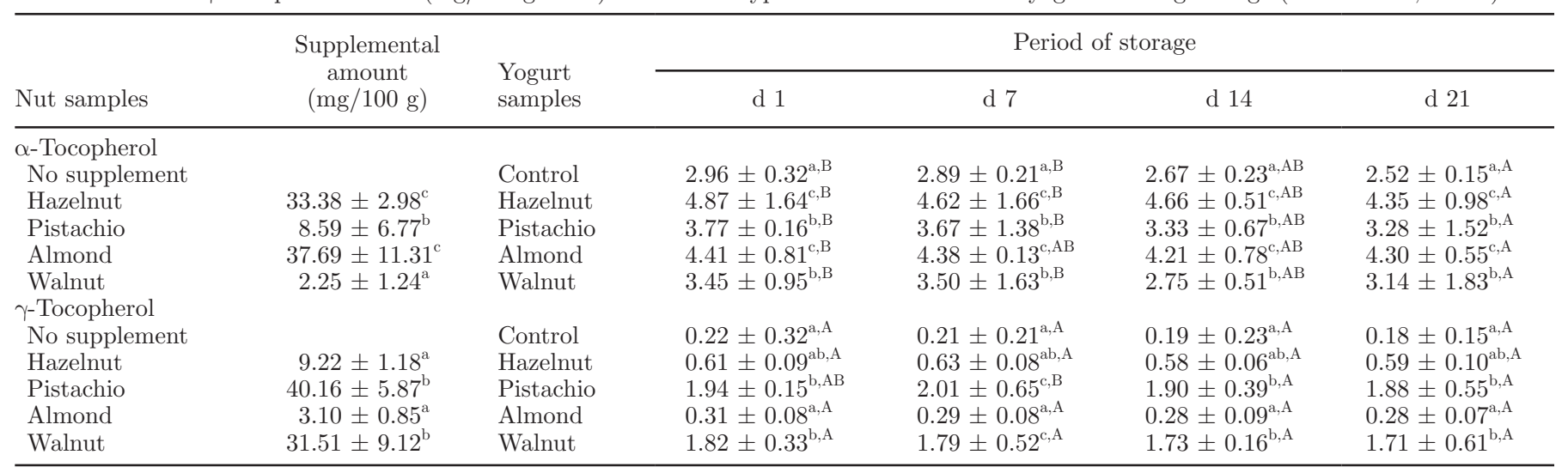

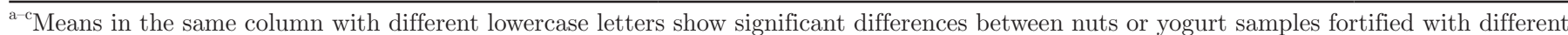
nut types $(P<0.05)$.

${ }^{\mathrm{A}, \mathrm{B}}$ Means in the same row with different capital letters show significant differences between storage periods $(P<0.05)$.
} 
most prevalent form of vitamin E, especially in nuts (Wagner et al., 2004). The levels of $\gamma$-tocopherol differed depending upon the nut type, and the values determined were similar to those of $\alpha$-tocopherol. Contents of $\gamma$-tocopherol were, in decreasing order, pistachio $>$ walnut $>$ hazelnut and almond; thus, the level of $\gamma$-tocopherol was highest in pistachio- and walnut-fortified yogurts (Table 4). Similar findings were reported by Kornsteiner et al. (2006), who noted that pistachio and walnut contained the highest $\gamma$-tocopherol contents and hazelnut and almond contained the highest $\alpha$-tocopherol contents among 10 different nut types. This finding is also in agreement with the results of Maguire et al. (2004). Both $\alpha$ - and $\gamma$-tocopherol values showed a tendency to decrease during storage in fortified yogurt samples; however, no significant differences were observed among days of storage $(P>0.05)$.

\section{Fatty Acid Content}

Table 5 shows the n- 3 and n- 6 fatty acid concentrations of oils extracted from nuts expressed in grams per $100 \mathrm{~g}$ of oil, and Table 6 presents fatty acid concentrations of fortified yogurt samples with those nuts. Our results indicate a high fat content among all 4 nut types, ranging between 52.37 (lowest for almond) and $69.54 \%$ (highest for walnut). Oleic acid was the most abundant fatty acid both in hazelnut, almond, and pistachio, whereas the most abundant fatty acid in walnut was linoleic acid, followed by oleic and linolenic acids. Linoleic acid was the second highest fatty acid in hazelnut, pistachio, and almond.

The concentrations of fatty acids determined in fortified yogurts were in proportion with the levels found in nut types. The other main contributing fatty acids for all nuts and fortified yogurts were palmitic (C16:0) and stearic acids (C18:0). Arachidic acid, EPA, and DHA showed lowest amounts among all fortified yogurt samples, whereas the walnut-fortified yogurts showed the highest amounts, particularly for EPA and DHA. Walnut yogurt was followed by pistachio and almond yogurts for arachidic acid and EPA, respectively; however, walnut yogurts had higher levels of linoleic and linolenic acid contents $(P<0.05)$. Control yogurt sample also included a certain amount of determined fatty acids arising from milk. All fortified yogurts showed similar values of stearic, oleic, and arachidic acids $(P>0.05)$. Hazelnut-, almond-, and pistachiofortified yogurts showed values close to that of control yogurt, mostly in terms of arachidic acid, EPA, and DHA, whereas walnut-fortified yogurt showed a notable change $(P<0.05)$ compared with control yogurt. During storage of all fortified yogurts, a slight but not

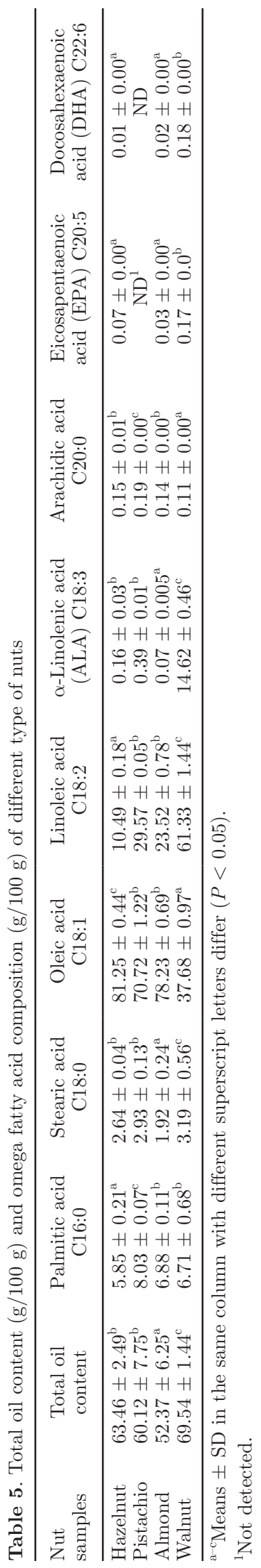




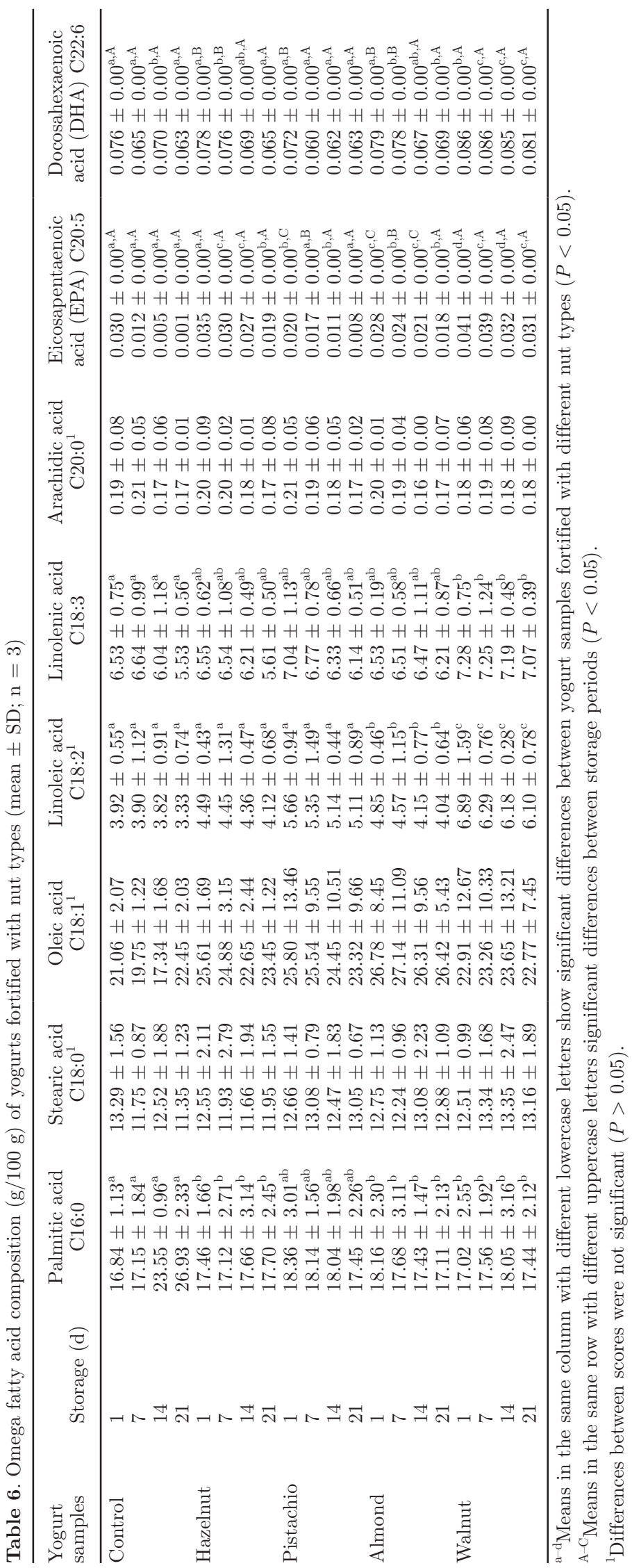


significant decrease was observed in fatty acids $(P>$ $0.05)$, except for EPA and DHA $(P<0.01)$.

In accordance with previous studies (Gecgel et al., 2011), walnut was identified as a significant source of n-3 and n-6 fatty acids, with higher contents of EPA, DHA, and arachidic acid compared with the other nuts. However, our data conform with literature data on fatty acid compositions of some nut types, such as walnut, pistachio, hazelnut, and almond (Gecgel et al., 2011; Maguire et al., 2004), and full-fat yogurt (Serafeimidou et al., 2013) regarding the concentration of fatty acids.

\section{CONCLUSIONS}

The results indicated that various nut types could be used to produce yogurts to increase some functional activities and health-promoting properties, as well as to improve some mechanical qualities. The study revealed that hazelnut and almond are good sources of $\alpha$-tocopherol. Yogurts fortified with hazelnut or almond provide a firmer structure and lower syneresis compared with yogurts fortified with pistachio or walnut. Yogurt fortified with walnut had some nutritionally important compounds, such as n-3 and n- 6 fatty acids, because walnut has higher proportions of EPA and DHA than other nuts. However, the use of walnut did not improve the instrumental textural characteristics of the final product. Supplementation of pistachio resulted in an increase in selenium concentration. All fortified yogurts had relatively higher protein, fat, and TS contents and acidity compared with control yogurt, and addition of nuts increased S. thermophilus and L. bulgaricus counts. The results of this study could be used to develop novel yogurts fortified with natural dried nuts as a source of bioactive compounds, which might be an alternative to fortification with synthetic chemical compounds that may cause adverse effects in consumers. The proper selection and use of nuts as a fortification material in yogurt appears to be important, as it provides a convenient food that satisfies consumer interest and provides health benefits.

\section{ACKNOWLEDGMENTS}

The authors thank The Scientific and Technological Research Council of Turkey (TUBITAK, Ankara, Turkey; Project code: TOVAG 113O407) for the financial support.

\section{REFERENCES}

Aithal, B. K., M. R. S. Kumar, B. N. Rao, N. Udupa, and B. S. Rao, 2009. Juglone, a naphthoquinone from walnut, exerts cytotoxic and genotoxic effects against cultured melanoma tumor cells. Cell Biol. Int. 33:1039-1049.
AOAC International. 1997. Official Methods of Analysis. AOAC International, Washington, DC.

Barbut, S. 1999. Determining water and fat holding. Pages 186-225 in Methods of Testing Protein Functionality. G. M. Hall, ed. Blackie Academic and Professional, New York, NY.

Barclay, M. N., A. Macpherson, and J. Dixon. 1995. Selenium content of a range of UK food. J. Food Compos. Anal. 8:307-318.

Benito, P., J. Caballero, J. Moreno, C. Gutierrez-Alcantara, C. Munoz, G. Rojo, S. Garcia, and F. C. Soriguer. 2006. Effects of milk enriched with $\omega-3$ fatty acid, oleic acid and folic acid in patients with metabolic syndrome. Clin. Nutr. 25:581-587.

Bertolino, M., S. Belviso, B. Dal Bello, D. Ghirardello, M. Giordano, L. Rolle, V. Gerbi, and G. Zeppa. 2015. Influence of the addition of different hazelnut skins on the physicochemical, antioxidant, polyphenol and sensory properties of yogurt. LWT Food Sci. Technol. 63:1145-1154.

Bes-Rastrollo, M., N. M. Wedick, M. A. Martinez-Gonzalez, T. Y. Li, L. Sampson, and F. B. Hu. 2009. Prospective study of nut consumption, long-term weight change, and obesity risk in women. Am. J. Clin. Nutr. 89:1913-1919.

Biesalski, H. K., L. O. Dragsted, I. Elmadfa, R. Grossklaus, M. Müller, D. Schrenk, P. Walter, and P. Weber. 2009. Bioactive compounds: Definition and assessment of activity. Nutrition 25:1202-1205.

Biliaderis, C. G., M. M. Khan, and G. Blank. 1992. Rheological and sensory properties of yogurt from skim milk and ultrafiltered retentates. Int. Dairy J. 2:311-323.

Boeneke, C. A., and K. J. Aryana. 2008. Effect of folic acid fortification on the characteristics of lemon yogurt. LWT Food Sci. Technol. 41:1335-1343.

Bradley, R. L. J., E. J. Arnold, D. M. Barbano, R. G. Semerad, D. E. Smith, and B. K. Vines. 1993. Chemical and physical methods. Pages 433-531 in Standard Methods for the Examination of Dairy Products. R. T. Marshall, ed. American Public Health Association, Washington, DC.

Cais-Sokolinska, D., and J. Pikul. 2004. Proportion of the microflora of Lactobacillus and Streptococcus genera in yoghurts of different degrees of condensation. Bull. Vet. Inst. Pulawy 48:443-447.

Chisholm, A., K. Mc Auley, J. Mann, S. Williams, and M. Skeaff. 2005. Cholesterol lowering effects of nuts compared with a Canola oil enriched cereal of similar fat composition. Nutr. Metab. Cardiovasc. Dis. 15:284-292.

Codex Alimentarius. 2011. Milk and Milk Products. 2nd ed. FAO and WHO, Rome, Italy.

Costa, P. A. D., C. A. Ballus, J. Teixeira-Filho, and H. T. Godoy. 2010. Phytosterols and tocopherols content of pulps and nuts of Brazilian fruits. Food Res. Int. 43:1603-1606.

Crittenden, R. G., N. R. Martinez, and M. J. Playne. 2003. Synthesis and utilisation of folate by yoghurt starter cultures and probiotic bacteria. Int. J. Food Microbiol. 80:217-222.

de Camargo Talon, L., E. P. de Oliveira, F. Moreto, K. C. PorteroMcLellan, and R. C. Burini. 2015. Omega-3 fatty acids supplementation decreases metabolic syndrome prevalence after lifestyle modification program. J. Funct. Food. 19:922-928.

Demirel, S., M. Tuzen, S. Saracoglu, and M. Soylak. 2008. Evaluation of various digestion procedures for trace elements of some food materials. J. Hazard. Mater. 152:1020-1026.

European Council. 2006. Nutrition and health claims made on foods. No:1924/2006. European Commission, Brussels, Belgium.

Folch, J., M. Lees, and G. H. Sloane Stanley. 1957. A simple method for the isolation and purification of total lipids from animal tissues. J. Biol. Chem. 226:497-509.

García-Pérez, F. J., Y. Lario, J. Fernández-López, E. Sayas, J. A. Pérez-Alvarez, and E. Sendra. 2005. Effect of orange fiber addition on yogurt color during fermentation and cold storage. Color Res. Appl. 30:457-463.

Gecgel, U., T. Gumus, M. Tasan, O. Daglioglu, and M. Arici. 2011 Determination of fatty acid composition of $\gamma$-irradiated hazelnuts, walnuts, almonds and pistachios. Radiat. Phys. Chem. 80:578-587.

Harris, L. J., and L. Ferguson. 2013. Improving the safety of almonds and pistachios. Pages 350-378 in Improving the Safety and Quality of Nuts. L. J. Harris, ed. Woodhead Publishing, London, UK. 
IDF. 1993. Determination of nitrogen content. Standard no. 20B. International Dairy Federation, Brussels, Belgium.

Isanga, J., and G. Zhang. 2009. Production and evaluation of some physicochemical parameters of peanut milk yoghurt. Food Sci. Technol. 42:1132-1138.

Kornsteiner, M., K. H. Wagner, and I. Elmadfa. 2006. Tocopherols and total phenolics in 10 different nut types. Food Chem. 98:381-387.

Kris-Etherton, P. M., G. Zhao, A. E. Binkoski, S. M. Coval, and T. D. Etherton. 2001. The effects of nuts on coronary heart disease risk. Nutr. Rev. 59:103-111.

Laiño, J. E., J. G. LeBlanc, and G. S. de Giori. 2012. Production of natural folates by lactic acid bacteria starter cultures isolated from artisanal Argentinean yogurts. Can. J. Microbiol. 58:581-588.

Lee, W. J., and J. A. Lucey. 2010. Formation and physical properties of yogurt. Asian-Australas. J. Anim. Sci. 23:1127-1136.

Lin, M. Y., and C. M. Young. 2000. Folate levels in cultures of lactic acid bacteria. Int. Dairy J. 10:409-413.

Lucey, J. A. 2002. Formation and physical properties of milk protein gels. J. Dairy Sci. 85:281-294.

Maguire, L. S. S. M. O'Sullivan, K. Galvin, T. P. O'Connor, and N. M. O'Brien. 2004. Fatty acid profile, tocopherol, squalene and phytosterol content of walnuts, almonds, peanuts, hazelnuts and the macadamia nut. Int. J. Food Sci. Nutr. 55:171-178.

Matumoto-Pintro, P. T., L. Rabiey, G. Robitaille, and M. Britten. 2011. Use of modified whey protein in yoghurt formulations. Int. Dairy J. 21:21-26.

Menard, M. K. 1997. Vitamin and mineral supplement prior to and during pregnancy. Obstet. Gynecol. Clin. North Am. 24:479-498.

Meyer, D., S. Bayarri, A. Tárrega, and E. Costell. 2011. Inulin as texture modifier in dairy products. Food Hydrocoll. 25:1881-1890.

NMKL. 2007. Trace elements- $\mathrm{As}, \mathrm{Cd}, \mathrm{Hg}, \mathrm{Pb}$ and other elements. Determination by ICP-MS after pressure digestion. Procedure No: 186, The Nordic Committee on Food Analysis, Oslo, Norway.

Palomo, M., A. M. Gutiérrez, M. C. Pérez-Conde, C. Cámara, and Y. Madrid. 2014. Se metallomics during lactic fermentation of Seenriched yogurt. Food Chem. 164:371-379.

Pelaes Vital, A. C., P. A. Goto, L. N. Hanai, S. M. Gomes-da-Costa, B. A. de Abreu Filho, C. V. Nakamura, and P. T. MatumotoPintro. 2015. Microbiological, functional and rheological properties of low fat yogurt supplemented with Pleurotus ostreatus aqueous extract. LWT Food Sci. Technol. 64:1028-1035.

Pereira, J. A., I. Oliveira, A. Sousa, P. Valentão, P. B. Andrade, I. C. Ferreira, F. Ferreres, R. Seabra, and L. Estevinho. 2007. Walnut (Juglans regia L.) leaves: Phenolic compounds, antibacterial activity and antioxidant potential of different cultivars. Food Chem. Toxicol. 45:2287-2295.

Ramirez-Santiago, C., L. Ramos-Solis, C. Lobato-Calleros, C. PenaValdivia, E. J. Vermon-Carter, and J. Alvarez-Ramirez. 2010.
Enrichment of stirred yogurt with soluble dietary fiber from Pachyrhizus erosus L. Urban: Effect on syneresis, microstructure and rheological properties. J. Food Eng. 101:229-235.

Ribarova, F., R. Zanev, S. Shishkov, and N. Rizov. 2003. a-Tocopherol, fatty acids and their correlations in Bulgarian foodstuffs. J. Food Compos. Anal. 16:659-667.

Rigotti, A. 2007. Absorption, transport, and tissue delivery of vitamin E. Mol. Aspects Med. 28:423-436.

Roman, M., A. Lapolla, P. Jitaru, A. Sechi, C. Cosma, G. Cozzi, P. Cescon, and C. Barbante. 2010. Plasma selenoproteins concentrations in type 2 diabetes mellitus - A pilot study. Transl. Res. $156: 242-250$.

Ros, E. 2010. Health benefits of nut consumption. Nutrients 2:652-682.

Sah, B. N. P., T. Vasiljevic, S. McKechnie, and O. N. Donkor. 2016. Physicochemical, textural and rheological properties of probiotic yogurt fortified with fibre-rich pineapple peel powder during refrigerated storage. LWT Food Sci. Technol. 65:978-986.

Serafeimidou, A., S. Zlatanos, G. Kritikos, and A. Tourianis. 2013. Change of fatty acid profile, including conjugated linoleic acid (CLA) content, during refrigerated storage of yogurt made of cow and sheep milk. J. Food Compos. Anal. 31:24-30.

Stokes, P., and K. Webb. 1999. Analysis of some folate monoglutamates by high-performance liquid chromatography-mass spectrometry. I. J. Chromatogr. A 864:59-67.

Świeca, M., Ł. Sęczyk, U. Gawlik-Dziki, and D. Dziki. 2014. Bread enriched with quinoa leaves - The influence of protein-phenolics interactions on the nutritional and antioxidant quality. Food Chem. $162: 54-62$

Tamime, A. Y., and R. K. Robinson. 1999. Yoghurt Science and Technology. Woodhead Publishing. London, UK.

Thomson, C. D. 2011. Effects of specific nuts and seeds. Pages 245-253 in Nuts and Seeds in Health and Disease Prevention. V. R. Preedy, R. R. Watson, B. Vinood, and V. B. Patel, ed. Academic Press, Cambridge, MA.

Tseng, A., and Y. Zhao. 2013. Wine grape pomace as antioxidant dietary fiber for enhancing nutritional value and improving storability of yogurt and salad dressing. Food Chem. 138:356-365.

Vasiljevic, T., T. Kealy, and V. K. Mishra. 2007. Effects of beta-glucan addition to a probiotic containing yogurt. J. Food Sci. 72:C405411.

Wagner, K. H., A. Kamal-Eldin, and I. Elmadfa. 2004. $\gamma$-TocopherolAn underestimated vitamin? Ann. Nutr. Metab. 48:169-188.

Wu, H., G. J. Hulbert, and J. R. Mount. 2001. Effects of ultrasound on milk homogenization and fermentation with yogurt starter. Innov. Food Sci. Emerg. Technol. 3:211-218. 